Quarterly Technical Progress Report July-September 2002 Intelligent Computing System for Reservoir Analysis and Risk Assessment of the Red River Formation

Cooperative Agreement DE-FC26-00BC15123

Luff Exploration Company Denver, Colorado

Award Date: March 1, 2000 Completion Date: August 31, 2003

Government Award: $\$ 2,254,550$

$\begin{array}{ll}\text { Project Manager: } & \begin{array}{l}\text { Kenneth D. Luff } \\ \text { Luff Exploration Company }\end{array} \\ \text { DOE Project Officer: } & \begin{array}{l}\text { Daniel Ferguson } \\ \text { National Petroleum Technology Office }\end{array}\end{array}$

Reporting Period: July through September 2002

U.S. DOE Patent Clearance is not required prior to the publication of this document 
Quarterly Technical Progress Report July-September 2002

\title{
Intelligent Computing System for Reservoir Analysis and Risk Assessment of the Red River Formation
}

\author{
COOPERATIVE AGREEMENT DE- FC26-00BC15123
}

\section{Disclaimer}

This report was prepared as an account of work sponsored by an agency of the United States Government. Neither the United States Government nor any agency thereof, nor their employees, makes any warranty, expressed or implied, or assumes any legal liability or responsibility for the accuracy, completeness, or usefulness of any information, apparatus, product, or process disclosed or represented that its use would not infringe privately owned rights. Reference herein to any specific commercial product, process, or service by trade name, trademark, manufacturer, or otherwise does not necessarily constitute or imply its endorsement, recommendation, or favoring by the United States Government or any agency thereof. The views and opinions of authors expressed herein do not necessarily state or reflect those of the United States Government or any agency thereof. 
Quarterly Technical Progress Report July-September 2002

\title{
Intelligent Computing System for Reservoir Analysis and Risk Assessment of the Red River Formation
}

\begin{abstract}
Integrated software has been written that comprises the tool kit for the Intelligent Computing System (ICS). Luff Exploration Company is applying these tools for analysis of carbonate reservoirs in the southern Williston Basin. The integrated software programs are designed to be used by small team consisting of an engineer, geologist and geophysicist. The software tools are flexible and robust, allowing application in many environments for hydrocarbon reservoirs. Keystone elements of the software tools include clustering and neural-network techniques. The tools are used to transform seismic attribute data to reservoir characteristics such as storage (phi-h), probable oil-water contacts, structural depths and structural growth history. When these reservoir characteristics are combined with neural network or fuzzy logic solvers, they can provide a more complete description of the reservoir. This leads to better estimates of hydrocarbons in place, areal limits and potential for infill or step-out drilling.

These tools were developed and tested using seismic, geologic and well data from the Red River Play in Bowman County, North Dakota and Harding County, South Dakota. The geologic setting for the Red River Formation is shallow-shelf carbonate at a depth from 8000 to $10,000 \mathrm{ft}$.

\section{Executive Summary}

Production results from recent demonstration wells are very encouraging. ICS has been used to predict reservoir quality and producing oil-cut at new horizontal laterals. Production results from wells are described in this report where the predicted producing oil-cut has been within $10 \%$ of the actual initial production from these wells. ICS tools have used with 2D seismic data to produce reservoir characterizations of producibility. Reservoir charcaterizations from ICS are being used in aiding computer simulation studies and formation of waterflood units. The project website traffic continues to increase. There were 927 visitors to the website during the third quarter.
\end{abstract}

\section{Summary of Technical Progress}

Well Activity

Production from demonstration wells has been compared to pre-drilling predictions made through ICS software. Figure 1 shows a map of predicted Red River B Zone oil-cut at original conditions (pre-production) for the Amor South Red River Unit with locations of horizontal drilling. About 1,524,000 bbl of oil has 
been produced from the unit area. At Amor South Red River Unit, three demonstration wells were completed during the third quarter. A new horizontal well (Schaaf I-6H) was drilled to be eventually completed for water injection service. After drilling operations were completed, the well was placed on pump to confirm the producing oil-cut as predicted along the lateral location. The placement of the lateral was designed to be down structure from the main oil accumulation and near a predicted producing oil-cut of $50 \%$ at original reservoir conditions. Early production from the well averaged 123 bopd and 180 bwpd with some drilling water yet to be recovered. An oil-cut of about $45 \%$ is anticipated after recovery of all drilling water. A horizontal re-entry lateral was drilled from the Nygaard 2-32 well at the Amor South Red River Unit. This lateral is located along the crestal axis of the reservoir. Production from the vertical completion averaged 35 bopd and 1 bwpd prior to driling the re-entry lateral. The average producing rate from the lateral has been 106 bopd and 20 bwpd. Horizontal laterals drilled from the Nygaard 2-31 resulted in an early production test of 93 bopd and 102 bwpd. Production from the vertical completion prior to the lateral drilling was 31 bopd and 9 bwpd. Production rates from the re-entry laterals support the rule-ofthumb that efficient laterals are capable of three times the rate compared to vertical completions. The producing oil-cuts at the laterals are in good agreement with the predictions made from ICS analysis especially when consideration is given to $1,524,000 \mathrm{bbl}$ cumulative oil after 22 years.

Confirmation of oil-cut at the location of the injection lateral is important in assessing the predicted reservoir limits and oil-in-place of the reservoir within the Amor South Red River Unit. Achieving an oil-cut of near 45\% at the Schaaf I-6H lateral validates the calculation of oil-in-place that was used for the waterflood design and project economics. The production results to-date also confirm the tilted reservoir limits that are predicted by ICS evalautions.

At Cold Turkey Creek Field, a re-entry lateral was drilled from the MuslowState B-27 well in the Red River D Zone. Shown on Figure 2 is a map of the predicted Red River D Zone oil-cut at original conditions (pre-production) with the location of the trajectory for the lateral from the Mulsow-State B-27 well.

Production from the re-entry lateral averaged 126 bopd and 35 bwpd after recovery of drilling water. The initial oil-cut from the vertical completion was $66 \%$ with an average of $52 \%$ over the first 24 months of production. The producing rate from the vertical completion just prior to drilling the re-entry lateral was 36 bopd and 103 bwpd for a producing oil-cut of $26 \%$. Results from the MuslowState B-27 lateral confirm inefficient drainage from the vertical completion which was suffering from water encroachment and coning.

Another test of an ICS prediction for producing oil-cut was performed at the Abrahamson D-8H in Grand River School Field. This well was a downstructure step-out from existing Red River B Zone production. Figure 3 shows a map of predicted Red River B Zone oil-cut at original (pre-production) conditions for a portion of the Grand River School Field with the location of the lateral that was drilled from the Abrahamson $\mathrm{D}-8 \mathrm{H}$. The expected producing oil-cut is shown to be between $55 \%$ and $60 \%$. Production from the re-entry lateral averaged 210 bopd and 117 bwpd after recovery of drilling water for an oil-cut of $65 \%$. 
In summary, the wells drilled during the 2002 drilling season have been generally successful confirmations of reservoir limits that were predicted by ICS analysis. One disappointing well that was drilled in 2001, Mrnak B-7 in Cold Turkey Creek Field, forced a re-evaluation of certain training data used in the ICS neural net. The Mrnak B-7 well encountered exellent quality reservoir rocks at the predicted structural depth but was wet in both the Red River B and D zones. In post evaluation, we added a regional trend depth to the training information and found that ICS will then predict that the well would encounter wetter reservoir rocks than previously predicted as the relative depth of the local structure is low to the regional depth trend.

ICS with 2D Seismic

ICS evaluations have been performed in areas with good 2D seismic coverage and well control. The reservoir analysis process with 2D seismic is similar to the process using 3D seismic. The main differences are the seismic attributes (amplitude and interval time, etc.) must be normalized and then gridded with conventional geologica mapping software. The map grid files of seismic attributes are used as if from a 3D seismic survey. At the North Buffalo Red River Unit, Harding County, South Dakota, ICS evaluations were performed to develop better reservoir characterizations for a computer simulation model. ICS was used to predict storage, transmissibility and production limits with well data and $2 \mathrm{D}$ seismic data.

Figure 4 shows a depth structure map of the Red River Formation at NBRRU. The depth structure computed from well control and seismic interval time data. The Red River B Zone reservoir at NBRRU has a basin-center tilt with respect to present-day structure.

With ICS, sesimic attributes are transformed to reservoir attributes. Figure 5 shows the ICS prediction of the Red River B cycle thickness from various seismic amplitudes and interval time. The B cycle thickness reflects the depositional setting for the B Zone dolomite reservoir. Shallow changes in water depth produce variation in reservoir porosity-thickness (phi-h) and quality (kh). The $B$ cycle thickness is one example the several seismic-reservoirs transformed attributes used for prediction of production attributes,

Transformed seismic-reservoir attributes are then transformed to production attributes using training from well data. Figure 6 shows the ICS prediction of producing oil-cut for the Red River B Zone reservoir at original (preproduction) conditions. Another transformation to a production attribute is shown in Figure7 where seismic-reservoir attributes were used to predict peak initial oil rate. The output files and maps from ICS evaluations can thus greatly aid in generating a computer simulation model for predicting primary and waterflood recovery with existing wells or hypothetical wells.

ICS as a reservoir characterization tool is being used with 2D seismic at two other fields to aid the assessment of reservoir limits and development strategies for waterflood units. At East Harding Springs Field, Harding County, South Dakota, ICS was used with 2D seismic data and well control to predict 
productive limits. Two plugged and abandoned wells were re-entered and drilled horizontally in the Red River B Zone. ICS evaluations indicated the reservoir limits to be much greater than previously thought based on the production history of the plugged wells which had been completed vertically in the Red River B, C and $\mathrm{D}$ Zones. Individual production rates after completion with horizontal laterals at the Swanson 1-32H and Dworshak 1-30H were 155 bopd with 110 bwpd and 192 bopd with 9 bwpd, respectively. The producing oil-cut at each well confirmed the predictions from the ICS analysis which was based on training of oil-cut from drill-stem test data from vertical wells in the surrounding area. The ICS reservoir characterizations are being used in computer simulation studies for the formation of a waterflood unit and corresponding development plan. Similar to the Red River B Zone reservoir at North Buffalo Red River Unit, the B Zone reservoir at East Harding Springs has a basin-center tilt with respect to present-day structure.

Computer reservoir simulation study and waterflood development plans are being aided with ICS evaluations at the North Amor Field area, Bowman County, North Dakota. At the Amor North Field area, a project demonstration lateral re-entry was drilled from the Gross 1-8 well to test the down-dip productive limits and oil-cut. The lateral was drilled 40 feet down-structure from the the vertical location. At this depth, the ICS prediction of producing oil-cut was less than $20 \%$. The decision to drill to this depth was based on encouraging drillcutting and gas detector shows as the lateral was drilled. Initial production from the lateral was 48 bopd and 266 bwpd for an oil-cut of $15 \%$. While the results from the well are economically dissappointing, they do provide validation of predictions of reservoir limits and will aid the delineation of reservoir area to be included in a future waterflood unit. The ICS evaluations will also be used for placement of other re-entry laterals from existing wells and possible new wells for the waterflood unit. ICS characterization at the North Amor Field area also indicates a basin-center tilt of the Red River B zone reservoir.

In lieu of acquisition of a new 3D seismic survey based on ICS evaluations of 2D seismic areas, we have decided to purchase certain 2D seismic lines from trade-data vendors. This is a slight modification from the original statement of work.

\section{Project Website}

During the third quarter, July-September 2002, there were 927 visitors to the project website. The average page views per visitor were 4.1 with an average duration of 4 minutes. From the file-type counter, the number of visitors who have downloaded the compiled software during the third quarter appears to be 16 and with 12 downloads of the software in native Matlab format. There was one request for the software in CD-ROM. Figure 8 is a screen capture of the website monitor for July through September. Figure 9 is a screen capture of the total visits by month since the beginning of 2002. We have added an optional information page for visitors to supply us with simple demographic information before proceeding to download the software; however, only a few visitors have 
elected to provide this information. Updated versions of ICS software tools are scheduled to be added to the website in the fourth quarter.

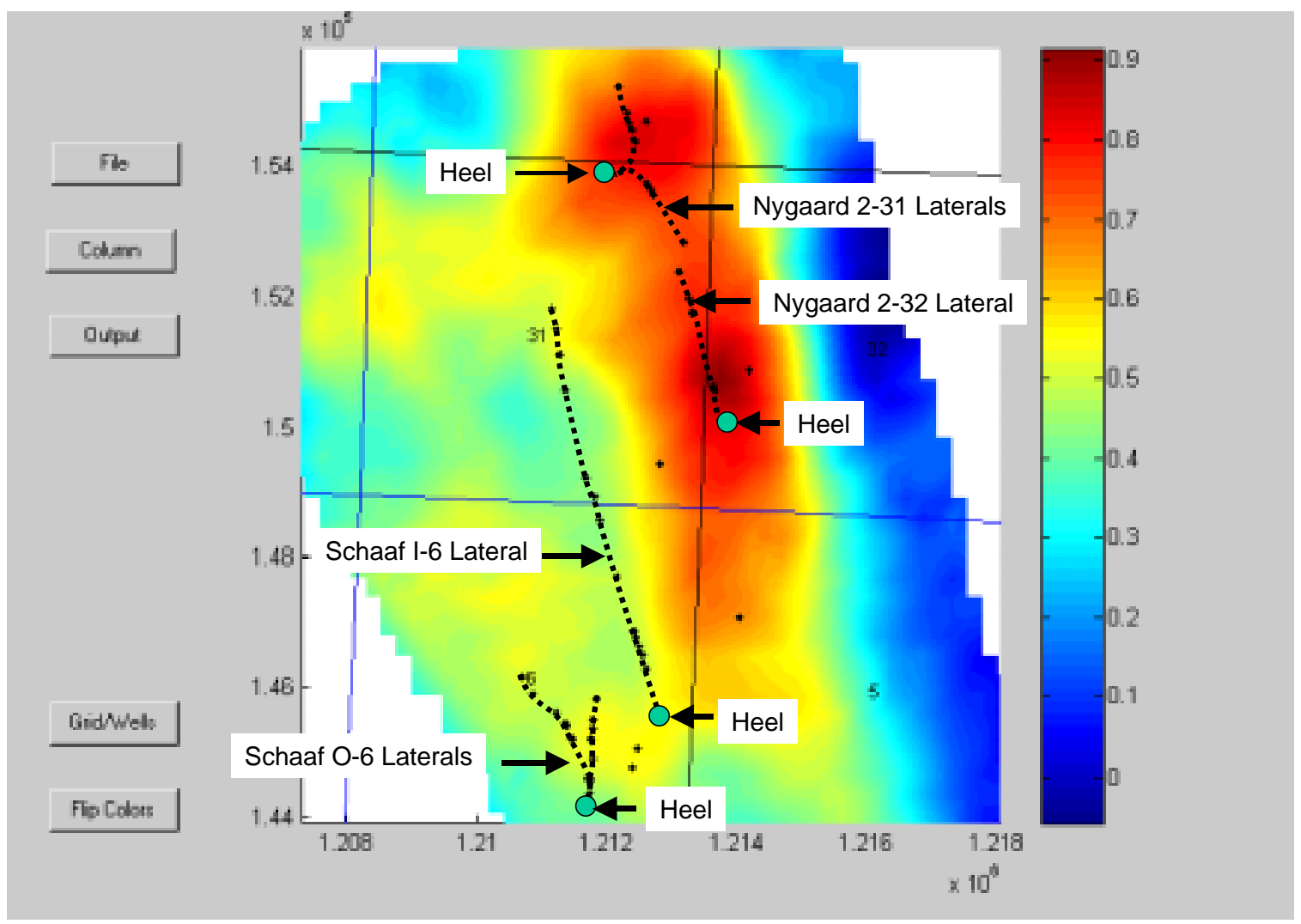

Figure 1. Map view of producing oil-cut prediction (original reservoir conditions) from ICS for the Red River B Zone at Amor South Red River Unit. The trajectories of horizontal laterals for four wells are indicated. Three demonstration wells were completed during the third quarter. The Schaaf I-6H was drilled and located as a future water injection well. Production testing of the Schaaf I-6 averaged 123 bopd and 180 bwpd after load recovery. The average producing rate from the Nygaard 2-32 lateral has been 106 bopd and 20 bwpd. Early production from the Nygaard 2-31 has averaged 93 bopd and 102 bwpd. The Schaaf O-6 was drilled in November 2000 , prior to ICS evalautions. The Schaaf O-6 was completed for an initial rate of 119 bopd and $95 \mathrm{bwpd}$. The field was discovered in 1979 and has a cumulative oil production of 1,524,000 bbl. 


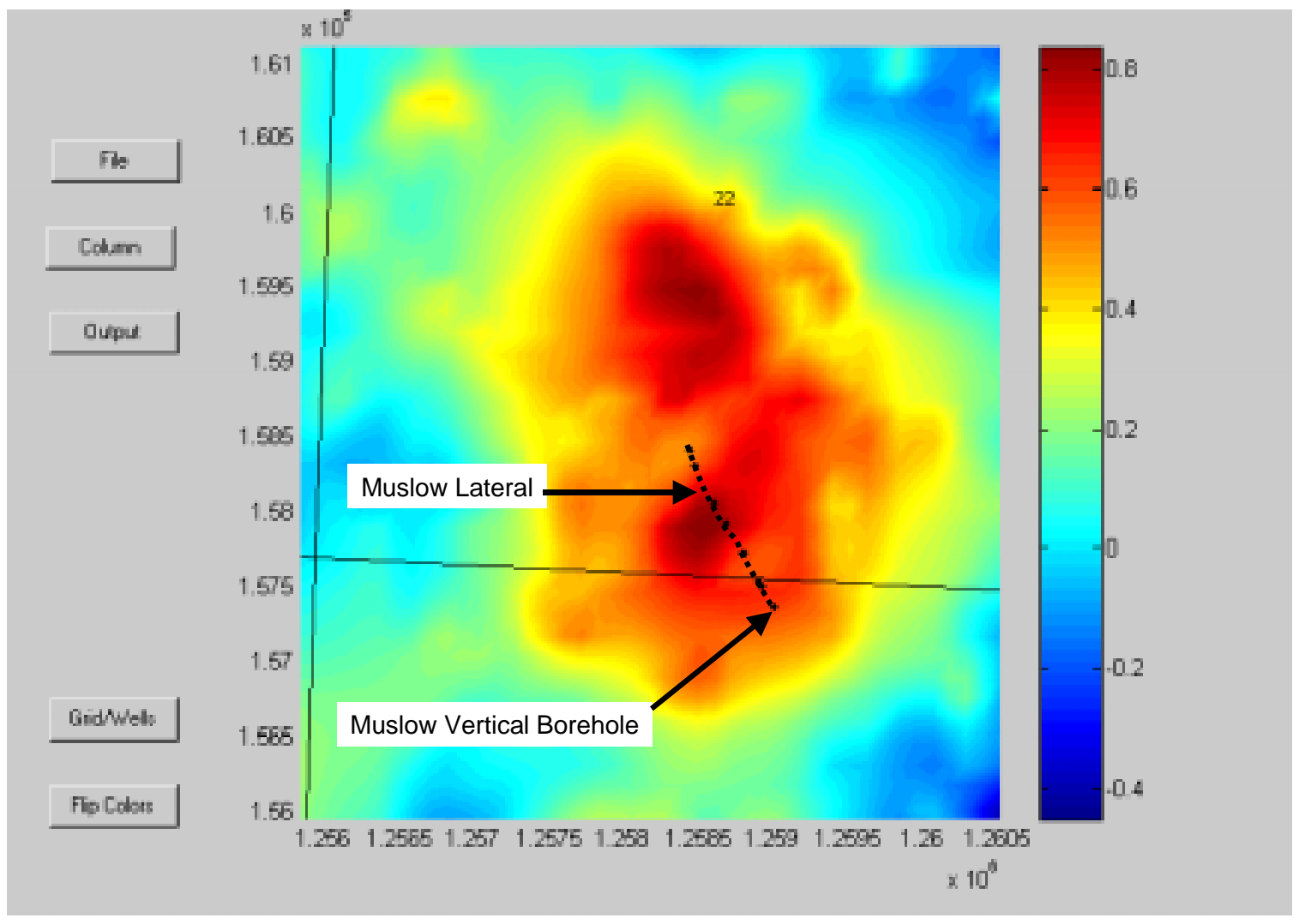

Figure 2. Map view of the predicted Red River D Zone oil-cut (original reservoir conditions) with the location of the trajectory for the lateral from the Mulsow-State B-27 well in Cold Turkey Creek Field. Production from the re-entry lateral averaged 126 bopd and 35 bwpd after recovery of drilling water. The initial oil-cut from the vertical completion was $66 \%$ with an average of $52 \%$ over the first 24 months of production. The producing rate from the vertical completion just prior to drilling the re-entry lateral was 36 bopd and 103 bwpd for a producing oil-cut of $26 \%$. 


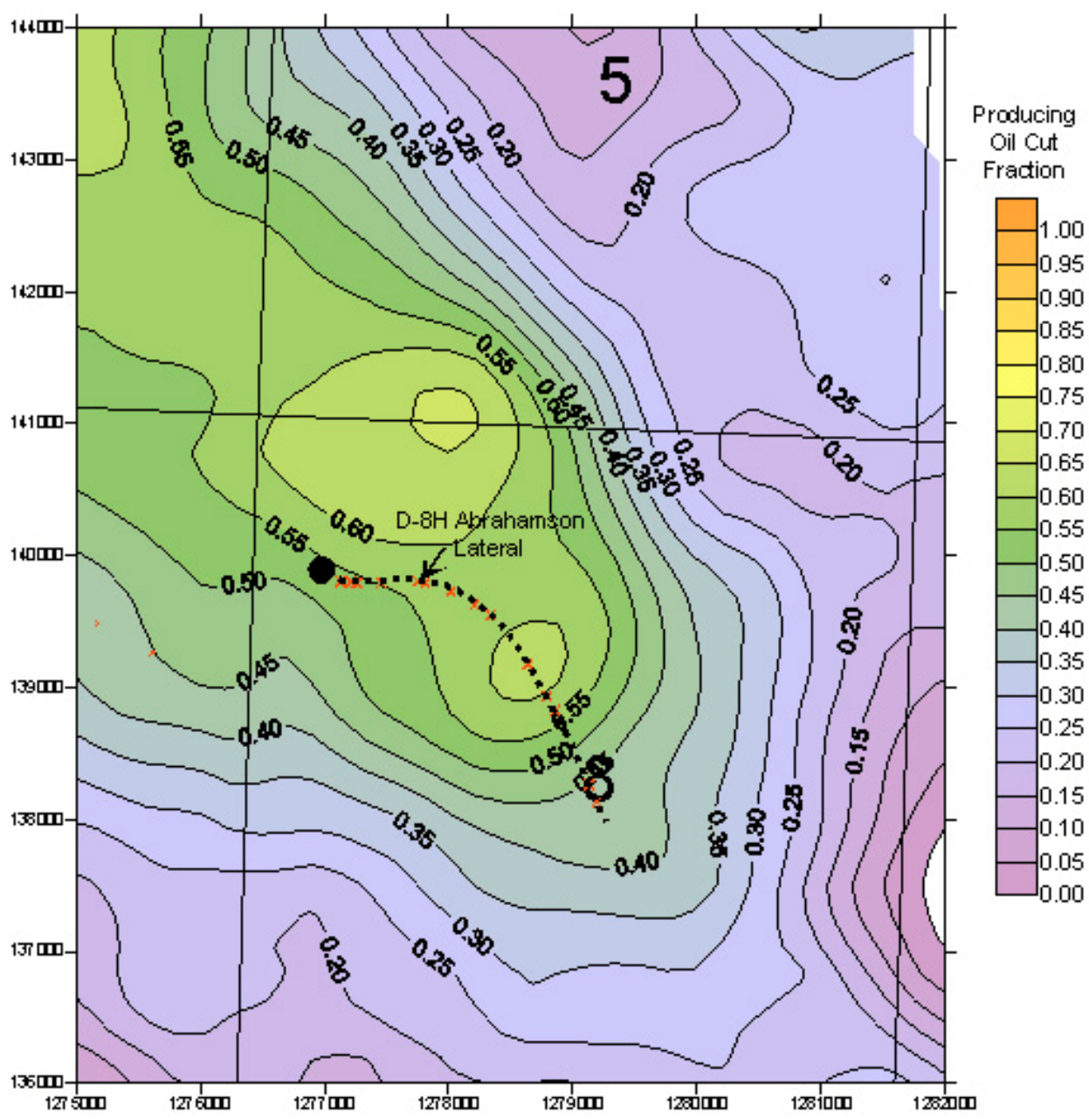

Figure 3. The figure shows a map of predicted Red River B Zone oil-cut at initial conditions for a portion of the Grand River School Field with the location of the lateral that was drilled from the Abrahamson D-8H. The expected producing oil-cut is shown to be between $55 \%$ and $60 \%$. Production from the re-entry lateral averaged 210 bopd and 117 bwpd after recovery of drilling water for an oil-cut of $65 \%$. 


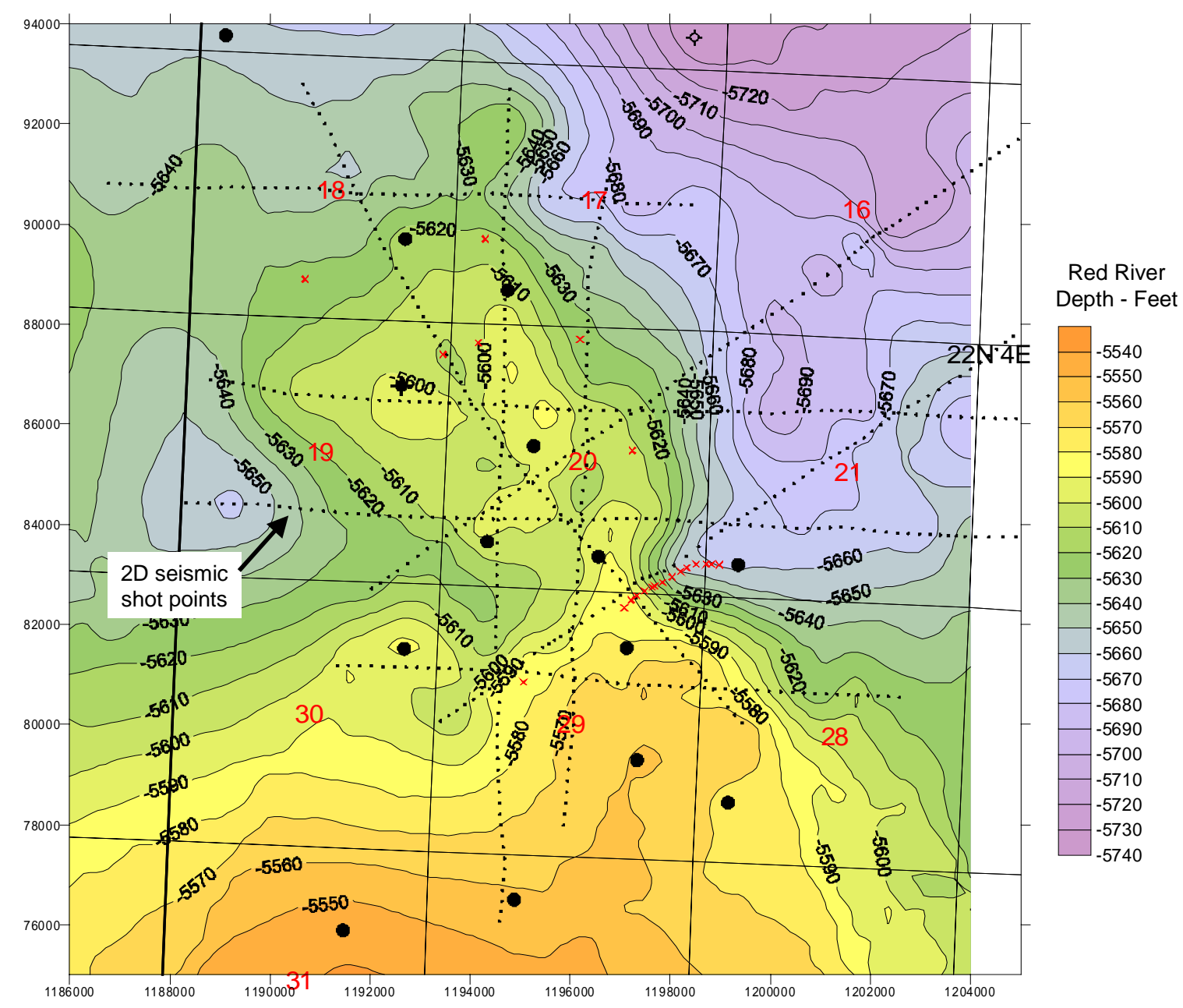

Figure 4. ICS tools have been successfully applied to areas with good 2D seismic coverage. The figure shows the depth structure of the Red River Formation at the North Buffalo Red River Unit in Harding County, South Dakota. The oil accumulation is tilted with respect to present-day structure. 


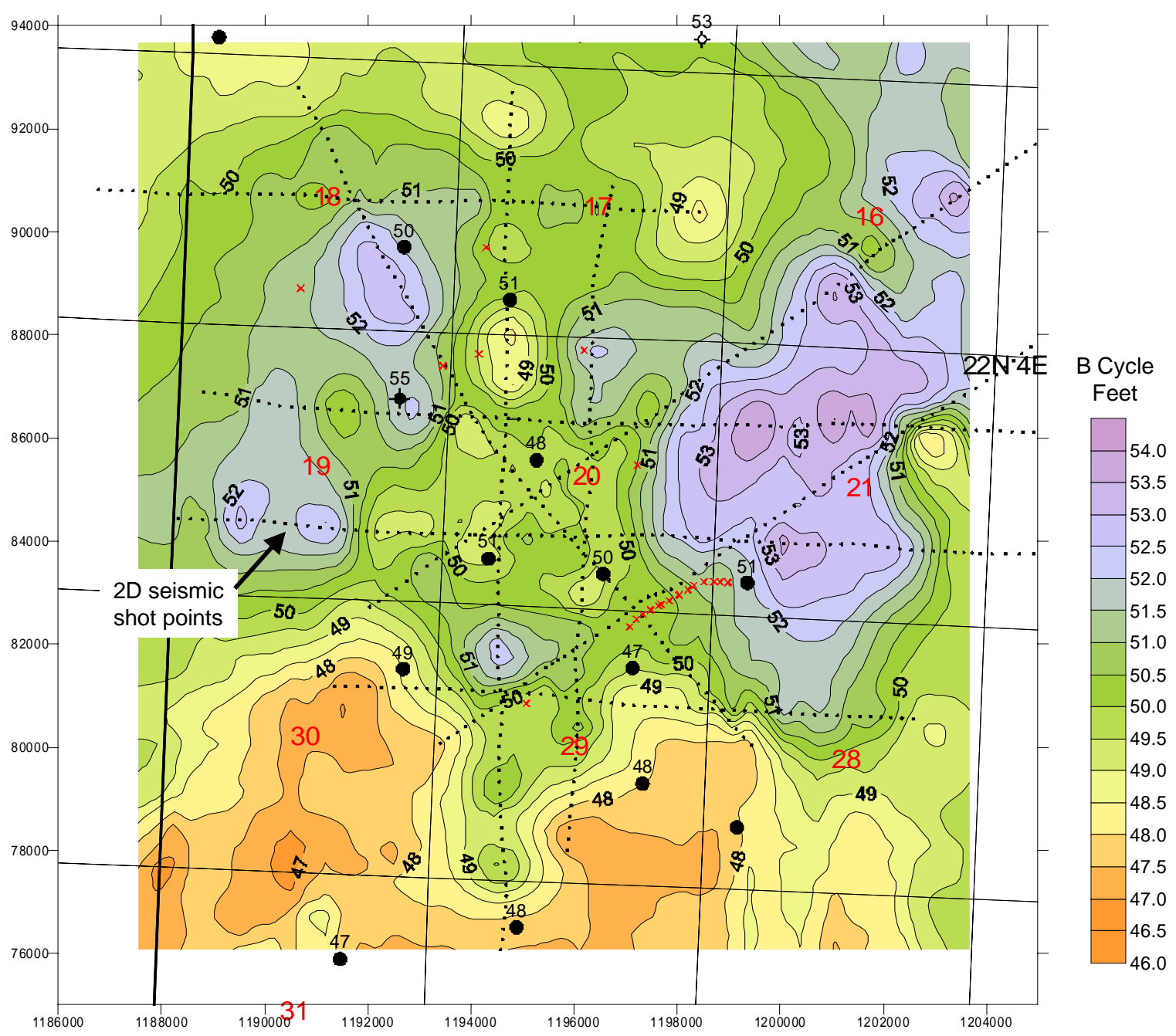

Figure 5. Sesimic attributes are transformed to reservoir attributes with ICS. The figure shows the ICS prediction of the Red River B cycle thickness from various seismic amplitudes and interval time. The B cycle thickness reflects the depositional setting for the B Zone dolomite reservoir. Shallow changes in water depth produce variation in reservoir porosity-thickness (phi-h) and quality (kh). The B cycle thickness is one example of several seismic-reservoir transformations used in the final prediction of production attributes. 


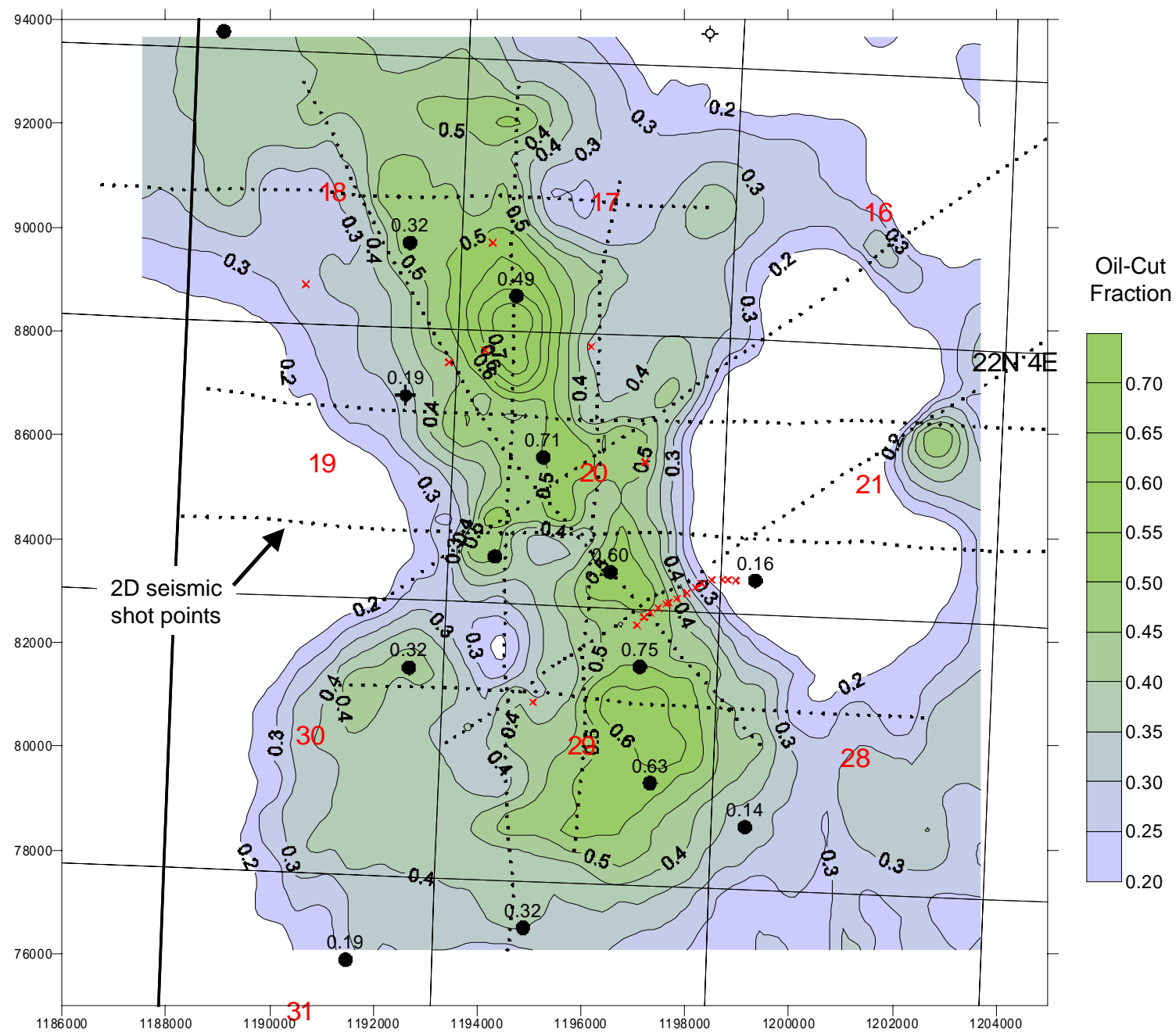

Figure 6. Transformed seismic-reservoir attributes are transformed to production attributes with ICS. The figure shows the ICS prediction of producing oil-cut for the Red River B Zone reservoir at original (pre-production) conditions. Reported initial oil-cut for the wells are labeled. 


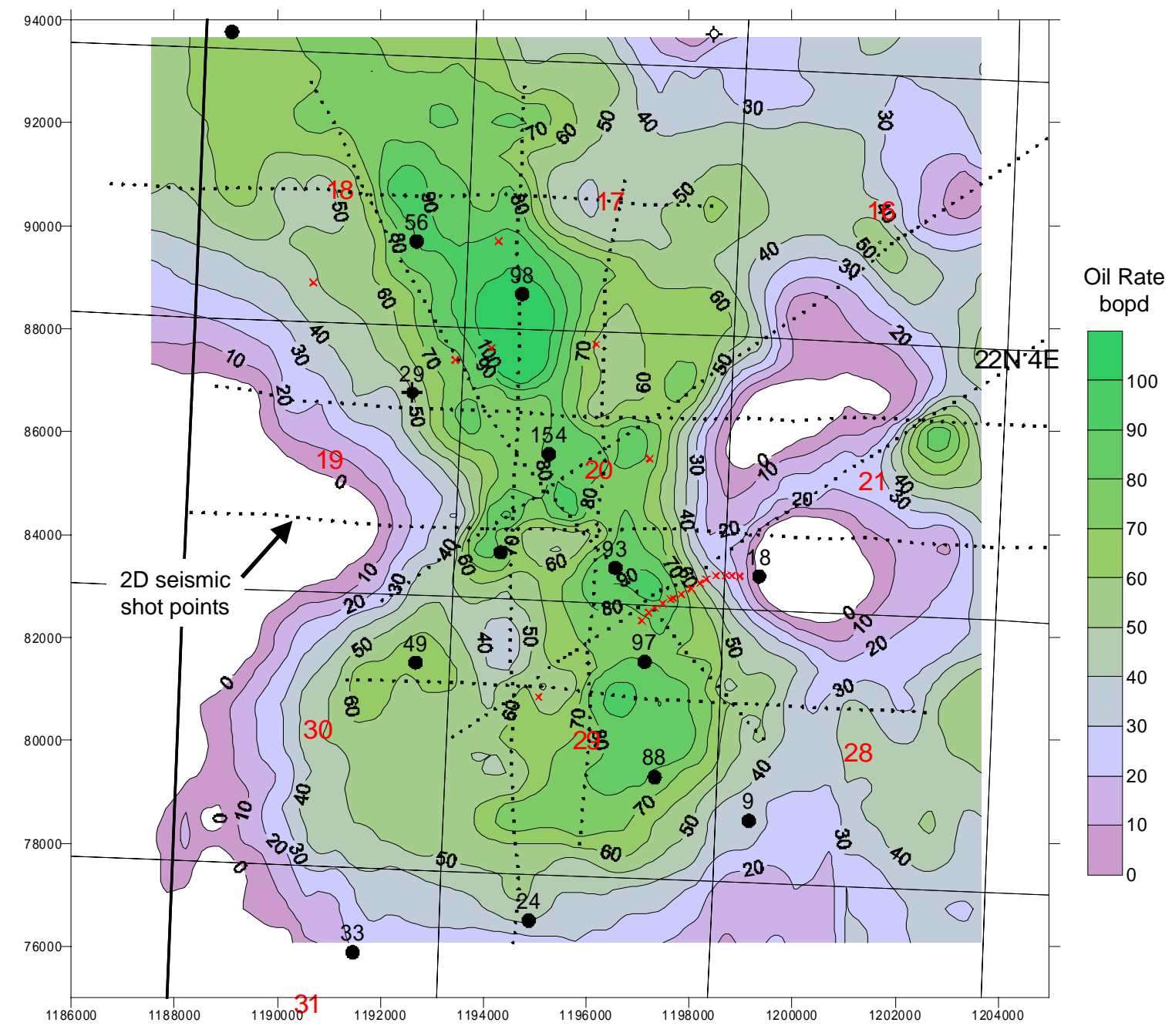

Figure 7. Transformed seismic-reservoir attributes are transformed to production attributes with ICS. The figure shows the ICS prediction of peak oil rate (bopd) for the Red River B Zone reservoir at original (pre-production) conditions. Reported peak oil rate (bopd) for the wells are labeled. 


\begin{tabular}{|lr|}
\hline & Summary \\
\hline Total Visitors & 927 \\
Total Pageviews & 3,834 \\
Total Hits & 15,456 \\
Total Bytes Transferred & $374.9 \mathrm{MB}$ \\
\hline Average Visitors Per Day & 10.07 \\
Average Pageviews Per Day & 41.67 \\
Average Hits Per Day & 168 \\
Average Bytes Transferred Per Day & $4.075 \mathrm{MB}$ \\
\hline Average Pageviews Per Visitor & 4.13 \\
Average Hits Per Visitor & 16.67 \\
Average Bytes Per Visitor & $414.1 \mathrm{~KB}$ \\
Average Length of Visit (H:M:S) & $00: 04: 27$ \\
\hline
\end{tabular}

Figure 8. A tabulation of statistics for the project website for July-September 2002.

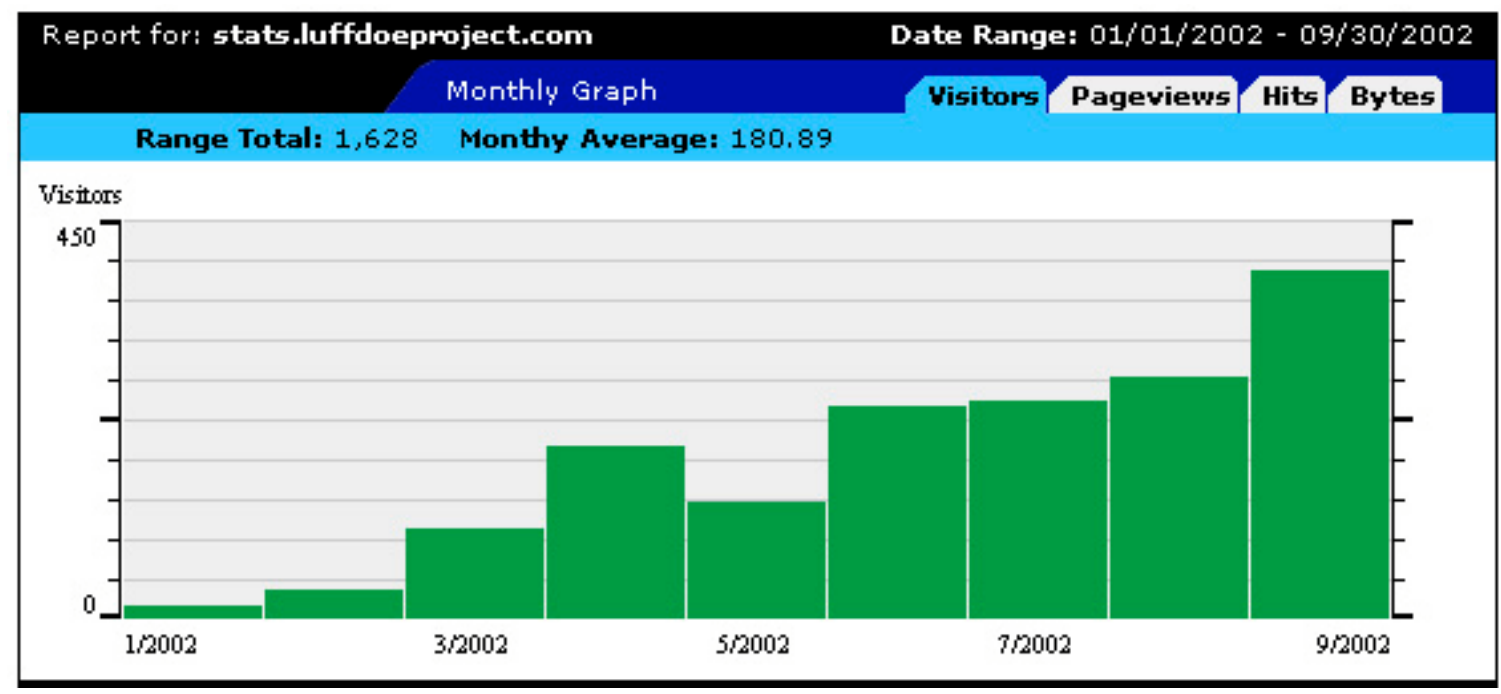

Figure 9. A graph of total visits by month since the beginning of 2002 . 